\title{
COMUNICAÇÃO E MÚLTIPLAS LINGUAGENS: VIVÊNCIAS PEDAGÓGICAS EM PROJETO INTEGRADOR
}

\author{
Cely Pessanha Cabral ${ }^{1}$ Karla Osiris Freire Leal Viana ${ }^{1}$ Patrícia Seixas Tinoco Rabelo \\ Patrícia Pinheiro Cardoso do Nascimento ${ }^{1}$ Ana Raquel de Souza Pourbaix ${ }^{1}$ \& Teresa \\ Claudina de Oliveira Cunha ${ }^{1 *}$
}

\begin{abstract}
RESUMO
CABRAL, C.P.; VIANA, K. O.F.L.; RABELO, P.S.T.; NASCIMENTO, P.P.C.; POURBAIX, A.R.S.; CUNHA, T.C.O. Comunicação e múltiplas linguagens: vivências pedagógicas em projeto integrador. Perspectivas Online: Humanas \& Sociais Aplicadas, v.10, n.28, p. 60-79, 2020.
\end{abstract}

A Comunicação e as diferentes manifestações da linguagem estão na ordem do dia, constituem nosso cotidiano. $\mathrm{Na}$ área educacional, é crescente o número de estudos e de vivências pedagógicas envolvendo $\mathrm{o}$ ato de comunicar e seus diferentes formatos na Era das Tecnologias Digitais da Informação e Comunicação (TDIC's). Neste contexto, apresenta-se no presente artigo uma pesquisa de natureza qualitativa, sob a forma de amostragem, de um projeto integrador, realizado em um curso de Pedagogia, no semestre 2019.2. Como metodologia de trabalho, utilizou- se a coleta de dados a partir das experiências de sala de aula, em diferentes disciplinas que compõem a matriz curricular do curso. Nossa hipótese é a de que comunicar, usando diferentes linguagens é parte da arquitetura da Educação ao longo da história sendo que, cada tempo sugere um novo estilo de expressão. Objetivou-se socializar práticas e estratégias pedagógicas trabalhadas de forma interdisciplinar, com metodologias ativas, a partir de movimentos comunicativos, capazes de tornar mais dinâmico e significativo o processo de ensino-aprendizagem.

Palavras-chave: Metodologias de Ensino; Interdisciplinaridade; Educomunicação. 


\title{
COMMUNICATION AND MULTIPLE LANGUAGES: PEDAGOGICAL EXPERIENCES IN THE INTEGRATING PROJECT
}

\begin{abstract}
Communication and the different manifestations of language are the order of the day, they constitute our daily life. In the educational area, there is an increasing number of studies and pedagogical experiences involving the act of communicating and its different formats in the Age of Digital Information and Communication Technologies (TDIC's). In this context, this article presents a qualitative research, in the form of sampling, of an integrative project, carried out in a Pedagogy course, in the 2019.2 semester. As a work methodology, data

collection from experiences was used classroom, in different subjects that make up the curricular matrix of the course. Our hypothesis is that communicating, using different languages is part of the architecture of Education throughout history, each time suggesting a new style of expression. The objective was to socialize pedagogical practices and strategies worked in an interdisciplinary way, with active methodologies, based on communicative movements, capable of making the teaching-learning process more dynamic and meaningful.
\end{abstract}

Keywords: Teaching Methologies; Interdisciplinarity; Educommunication.

\footnotetext{
${ }^{1}$ Institutos Superiores de Ensino do CENSA - ISECENSA - Laboratório de Formação de Professor - LAFORP - Rua Salvador Correa, 139, Centro, Campos dos Goytacazes, RJ, CEP: 28035-310, Brasil.

(*) e-mail: trcocunha@gmail.com

Data de recebimento: 01/05/2020. Aceito para publicação: 28/05/2020. Data da publicação: 23/06/2020.
}

Persp. Online: hum \& sociais aplicada., Campos dos Goytacazes, 28 (10)60-79- 2020 seer.perspectivasonline.com.br 


\section{PERSPECTIVASonline}

\section{INTRODUÇÃO}

A determinação sobre a qual versa este trabalho, ou seja, a gênese do estudo, surgiu por ocasião de leituras, de vivências, de aprendizagens teórico-práticas no meio acadêmico e profissional. Busca apresentar e analisar as estratégias de ensino concretamente desenvolvidas por docentes do ensino superior junto a discentes de um curso de formação de docente, em uma instituição de ensino superior privada do Estado do Rio de Janeiro.

O estudo empreendido tem um enfoque qualitativo, com objetivos exploratórios e analíticos. A pesquisa estabelece um processo único de interpretação, pois define um grupo para estudo, discentes matriculados no $6^{\circ}$ período de um de Curso de Pedagogia. A partir da integração de 08 (oito) disciplinas estabeleceu-se um eixo integrador e interdisciplinar considerando o uso de metodologia ativas de aprendizagem.

Projetos integradores (interdisciplinares) representam uma fase mais elaborada de projetos e ações que unem mais de uma disciplina, docentes e áreas de conhecimento. Integram vários pontos de vista e saberes, por meio de questões diversas do cotidiano e buscam possibilitar aos discentes a percepção das ligações entre as disciplinas. Podem ser desenvolvidos dentro e fora da sala de aula (BACICH; MORAN, 2018).

O tema integrador foi a "Comunicação e suas múltiplas linguagens", com um eixo norteador "As interfaces do ato comunicativo", por meio de um planejamento integrado e estratégico e a conexão com as diferentes manifestações da linguagem do profissional do século

Para tanto, apresentou-se a seguinte questão problema: como a comunicação pode ser um elemento facilitador nos diferentes espaços educacionais e sociais?

Para o desenvolvimento dos conceitos das disciplinas que compõe a matriz curricular do curso, estabeleceu-se como recurso metodológico a aprendizagem invertida, objetivando uma comunicação didática integrada e efetiva entre os atores do processo ensino e aprendizagem. Para Pedroso e Pinto (2019, p. 171), mesmo apoiada em uma matriz organizada por disciplinas, pode-se garantir "organicamente que alguns tópicos comuns aos conteúdos" possam ser "direcionados para um mesmo objetivo formativo".

O modelo de pedagogia utilizado considerou as diversas possibilidades de inversão dos fatores espaço, tempo e atividades no contexto das disciplinas, o que possibilitou aos docentes a liberdade de planejar aulas ativas e criativas que melhor atendessem as demandas dos discentes (TALBERT, 2019). Todo o diálogo didático docente-discente foi mediado pela sala de aula presencial (síncrono) e pelas mídias (assíncronas).

O diálogo didático realizado de forma assíncrona não estabelece um tempo e espaço de encontros pré-determinados. Para Talbert (2019, p. 11) a aprendizagem invertida não demanda "[...] horário de aula ou pré-aula - existe apenas o tempo, e a forma como ele é usado depende da escolha individual do aluno no momento, e essas escolhas criam os contextos do espaço individual ou grupal. [...]".

Flipped Learning Network (2014 apud TALBERT, 2019) indica que a aprendizagem invertida envolve quatro pilares: flexibilidade, cultura de aprendizagem, conteúdo intencional e educador profissional.

$>$ Ambiente flexível - significa o reconhecimento de que discentes aprendem de forma e ritmos diferentes, o que demanda flexibilidade por parte dos docentes na elaboração de

Persp. Online: hum \& sociais aplicada., Campos dos Goytacazes, 28 (10)60-79- 2020 seer.perspectivasonline.com.br 
planos de ensino e ajustes em suas práticas.

$>$ Cultura de aprendizagem - indica a valorização do processo de aprendizagem em todos os seus formatos, considerando as potencialidades e fragilidades que se fazem presentes, tendo o discente como o protagonista. $\mathrm{O}$ docente fornece apoio e feedback.

$>$ Conteúdo intencional - por meio de material e espaços diversificados (vídeos, textos, jogos, laboratórios, entre outros), com conexões explícitas com focos de aprendizagem claramente determinados possibilita-se o trabalho de forma significativa.

$>$ Educador profissional - demanda do docente a preparação de conteúdo e a organização do espaço de aprendizagem, assim como a observação dos discentes enquanto trabalham, a intervenção quando necessário (garantindo a autonomia) e avaliação de todo o processo.

O tempo da sala de aula presencial é propício para um diálogo didático efetivo, utilizando instrução direta e aprendizagem ativa, enquanto ferramentas (aulas expositivas, apoio aos grupos para o desenvolvimento das atividades, debates, seminários, rodas de conversa), de aplicação, análise e práticas pedagógicas, por meio da mediação do docente. Dessa forma, a criação de espaços de aprendizagem que maximizem tempo, espaços e atividades beneficiam a rotina de estudos. $\mathrm{O}$ ambiente em grupos possibilita uma aprendizagem interativa e dinâmica em que docentes atuam como mediadores, orientadores para os discentes (BERGMANN, 2018; TALBERT, 2019).

A abordagem de uma aprendizagem invertida não representa simplesmente uma "nova" técnica de ensino, mas acima de tudo um novo design de prática de ensino e de atuação profissional. Sem dúvida, demanda a quebra de paradigmas por parte dos docentes na medida em que se deve "trabalhar no sentido de ir além dos métodos e das técnicas" a partir da integração teoria e prática. $\mathrm{O}$ mesmo ocorre com os discentes quando se observa ainda existir a expectativa por receber "receitas prontas" (ELIAS; FELDMANN, 2013, p. 111).

\section{METODOLOGIA}

Este estudo de natureza aplicada possui enfoque qualitativo. O campo de observação e análise compreendeu 48 (quarenta e oito) discentes matriculados no $6^{\circ}$ período, de um curso de Pedagogia do Estado do Rio de Janeiro, no segundo semestre de 2019.

O processo de ensino utilizando-se das metodologias ativas e personalizadas de aprendizagem considerou não somente fator logístico, mas acima de tudo a diversidade de estilos de aprendizagem e a inclusão dos discentes. Por meio da aprendizagem invertida, pode- se indicar os pontos de maior dificuldade e resistência apresentados pelos discentes no contato com o conteúdo e propostas de trabalho apresentados, de posse das informações o docente ajusta conteúdos (aprofundando tópicos e conceitos) e práticas de ensino.

Diferentes estratégias foram utilizadas para operacionalização deste projeto, a saber:

Aula expositiva

$>$ Aula invertida

$>$ Análise e produção de vídeos

$>$ Visita técnica a Laboratório

$>$ Produção de ideias criativas e práticas no Espaço Maker

$>$ Registro das ações integradas e interdisciplinares no Aplicativo Trello

$>$ Utilização de aplicativos (Mirror, Kahoot, SurveyMonkey, Canvas)

$>$ Construção de Infográficos e Mapas Conceituais temáticos

$>$ Seminários temáticos

Persp. Online: hum \& sociais aplicada., Campos dos Goytacazes, 28 (10)60-79- 2020 seer.perspectivasonline.com.br 
Cada estratégia foi apresentada para os discentes sempre buscando uma clareza dos objetivos da aprendizagem a serem atingidos, considerando a taxonomia de Bloom (1956): Conhecimento, Compreensão, Aplicação, Análise, Síntese e Avaliação. As etapas eram discutidas e sempre alteradas em função de demandas surgidas.

O aplicativo Trello foi utilizado como uma ferramenta de colaboração (docentes e discentes), como um quadro virtual. Trata-se de uma ferramenta dinâmica e flexível de gerenciamento de projetos, de colaboração, que pode ser acessado via web e por meio de seu smartphone ou tablet. Por meio do referido ambiente virtual, cada disciplina pode organizar e informar de forma assíncrona as atividades propostas e desenvolvidas sob a forma de quadros. As ações desenvolvidas eram registradas por meio de um suporte midiático no momento de sua criação e acessadas pelos discentes e docentes ao mesmo tempo ou em um momento posterior.

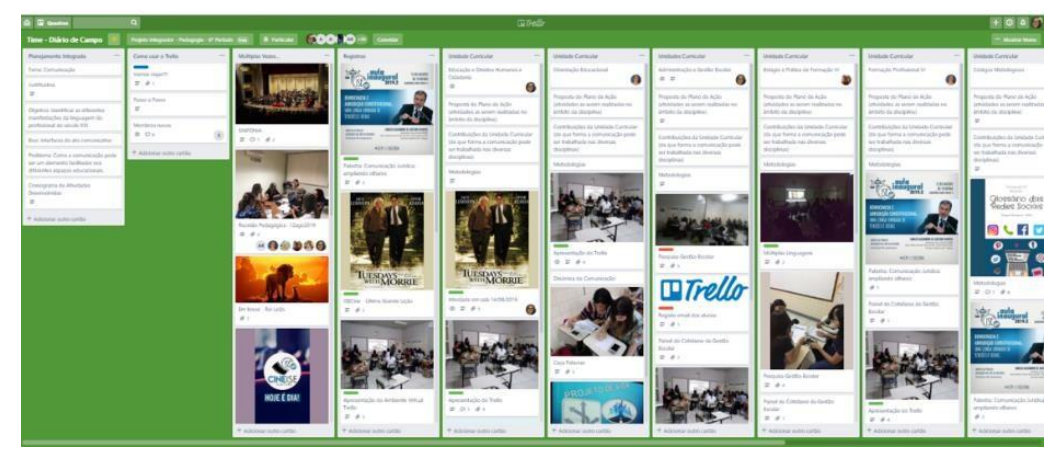

Figura 1: Quadro Virtual que abriga o Projeto.

Fonte: https://trello.com/b/OEEH75AE/time-di\%C3\%A1rio-de-campo

No que diz respeito ao ambiente virtual de aprendizagem/Trello (Figura 1), a orientação para o cadastro dos discentes foi realizada em sala de aula, buscando garantir que todos tivessem o acesso ao aplicativo/plataforma e que as dúvidas quanto ao uso do aplicativo fossem atendidas. Todo esse processo ocorreu de forma colaborativa entre docentes-discentes e discentes-discentes. Ressalta-se que todos discentes foram orientados a fazer o download do aplicativo em seus celulares. No entanto, nem todos conseguiram fazer em função de limites técnicos/tecnológicos.

No ambiente virtual, foi criado um "Time", denominado "Diário de Campo", com cinquenta e quatro membros (seis docentes e quarenta e oito discentes). A ferramenta possibilitou o registro e a socialização de materiais/atividades, links, vídeos, textos, imagens ao longo do semestre.

\section{RESULTADOS}

O presente estudo busca apresentar uma prática inovadora, integradora e interdisciplinar desenvolvida no segundo semestre de 2019, por 06 (seis) docentes que atuam em um curso de graduação de formação de docentes, em um município do Estado do Rio de Janeiro.

A partir da proposta apresentada, pela coordenação do curso para implementação de projetos "dentro de uma perspectiva integrada nos conhecimentos específicos" optou-se pela realização de ações integradoras e interdisciplinares, com um eixo integrador "Interfaces do Ato Comunicativo". utilizadas.

Nesta etapa do estudo serão apresentados resultados obtido a partir de algumas estratégias

\section{1. "Hora de brincar de designer!" - Educação, Direitos Humanos e Cidadania em diálogo}

Persp. Online: hum \& sociais aplicada., Campos dos Goytacazes, 28 (10)60-79- 2020

seer.perspectivasonline.com.br 
Na disciplina Educação e Direitos Humanos, o eixo "Interface do Ato Comunicativo" foi apresentado, principalmente, por meio da proposta de construção de infográficos temáticos que abordassem a Declaração Universal dos Direitos Humanos.

A teoria de aprendizagem (pressuposto pedagógico) trabalhou as competências/habilidades previstas nas Diretrizes Curriculares Nacionais para um Curso de Pedagogia: trabalho em equipe; desenvolvimento de ideias; diversidade cultural; cidadania; reflexão e tomada de decisão.

O objetivo principal dessa ação foi possibilitar ao discente a compreensão das bases conceituais e históricas dos Direitos Humanos, da reconstrução histórica no processo de afirmação dos direitos humanos na sociedade brasileira, contribuindo para a formação crítica, ética, social e política do discente.

Quanto às estratégias de personalização/adaptação, respeitando-se o tempo, ritmo e forma de aprender de cada aluno, adotou-se os seguintes passos:

Passo 1: Verificação do conhecimento prévio dos discentes sobre o tema: O que é a ONU? O que são direitos humanos? Você tem Direitos Humanos?; Aula expositiva (natureza predominantemente teórica);

Passo 2: Apresentação de vídeo "Os 30 Artigos da Declaração Universal dos Direitos Humanos";

Passo 3: Material ilustrativo; Apresentação do Aplicativo Trello (quadro virtual);

Passo 4: Apresentação da proposta da Construção de um Infográfico (divisão da turma em grupos de trabalho; distribuição de um documento contendo as instruções principais da atividade a ser desenvolvida); Como atividade complementar, entregou-se uma folha de Orientação Planejamento para a produção de infográfico.

Os discentes foram divididos em equipes, com no máximo 5 membros. As atividades foram desenvolvidas em espaços diversos: sala de aula, Sala Maker da instituição e fora da sala de aula.

Para a realização das atividades foram disponibilizados alguns recursos materiais, digitais e audiovisuais, descritos a seguir:

$\checkmark$ Apresentação do DVD "A História dos Direitos Humanos" - filme educacional que apresenta a história dos direitos humanos, que culmina num único documento universal: a Declaração Universal dos Direitos do Homem;

$\checkmark$ Distribuição do Folheto ilustrado "O que são os Direitos Humanos?;

$\checkmark$ Utilização do ambiente virtual de aprendizagem Trello como um sistema de quadro virtual;

Apresentação e entrega concreta de modelos de infográficos (temas variados).

Persp. Online: hum \& sociais aplicada., Campos dos Goytacazes, 28 (10)60-79- 2020 seer.perspectivasonline.com.br 
Tabela 1: Da Organização dos Espaços de Aprendizagem

\begin{tabular}{|c|c|c|c|c|}
\hline Espaços & Atividade & Duração & Papel do Aluno & Papel do Docente \\
\hline $\begin{array}{l}\text { Sala de } \\
\text { aula }\end{array}$ & $\begin{array}{l}\text { Construção } \\
\text { de } \\
\text { Infográfico }\end{array}$ & $2 \mathrm{~h} / \mathrm{a}$ & $\begin{array}{l}\text { Divisão dos grupos; } \\
\text { primeiras questões } \\
\text { apresentadas. }\end{array}$ & $\begin{array}{l}\text { Neste primeiro contato, por } \\
\text { meio de uma aula expositiva } \\
\text { (revisão do Tema), } \\
\text { apresentou-se a proposta da } \\
\text { atividade a ser desenvolvida: } \\
\text { Infográfico. Distribuição de } \\
\text { material de apoio; } \\
\text { apresentação do vídeo sobre } \\
\text { Declaração Universal de } \\
\text { Direitos } \\
\text { Humanos. }\end{array}$ \\
\hline $\begin{array}{l}\text { Sala de } \\
\text { aula }\end{array}$ & $\begin{array}{c}\text { Construção } \\
\text { de } \\
\text { Infográfico }\end{array}$ & $2 \mathrm{~h} / \mathrm{a}$ & $\begin{array}{l}\text { Em grupos deram } \\
\text { início a escolha do } \\
\text { tema. Escolha do } \\
\text { tema a ser construído } \\
\text { para o Infográfico }\end{array}$ & $\begin{array}{l}\text { Orientação aos grupos; } \\
\text { Distribuição da Ficha } \\
\text { "Planejamento para a } \\
\text { construção do Infográfico" }\end{array}$ \\
\hline Sala Maker & $\begin{array}{c}\text { Construção } \\
\text { de } \\
\text { Infográfico }\end{array}$ & $2 \mathrm{~h} / \mathrm{a}$ & $\begin{array}{l}\text { Grupos reunidos, em } \\
\text { um espaço diferente. } \\
\text { Todos com notebook } \\
\text { e material para } \\
\text { leitura e construção } \\
\text { dos Infográficos }\end{array}$ & $\begin{array}{l}\text { Orientação e atendimento } \\
\text { aos grupos. }\end{array}$ \\
\hline
\end{tabular}

Fonte: Pesquisa de Campo própria.

Ao final dos trabalhos produzidos pelos discentes, adotou-se os seguintes critérios avaliativos:

1. A proposta apresentada aos alunos resultou numa participação muito ativa. Pode-se observar, no entanto, que acesso ao ambiente virtual Trello só ocorria mediante uma "provocação" por WhatsApp. Para tanto, decidiu-se pela criação de um grupo no Whatzapp, com um membro (representante) de cada grupo;

2. A verificação se deu a partir de cada "espaço grupal", da participação dos grupos em sala de aula somada às postagens individuais (representantes dos grupos); da apresentação do trabalho finalizado;

3. Como critérios de avaliação foram considerados: objetivos propostos + Estratégias e recursos utilizados + Participação momento presencial (grupos) e online (individual) + trabalho realizado; interação docente-discente.

4. Dos ajustes/adaptação: a mudança "sala de aula tradicional" para a "sala maker" representou o ajuste/adaptação. Sem dúvida, a questão design do ambiente (espaço, distribuição das mesas e cadeiras) gerou uma participação decisiva dos discentes, na aprendizagem interativa e dinâmica em que o docente pode orientar os discentes enquanto aplicavam os conceitos e se envolviam de forma criativa na tarefa proposta (TALBERT, 2019). Nesse momento, cada grupo tinha um notebook (solicitação em momento anterior) o que possibilitou um crescimento e envolvimento muito positivo na realização das atividades. 
Os infográficos construídos pelos discentes abordaram os artigos: "Direito à Comunicação"; "Direito à Educação"; "Somos todos iguais perante a Lei"; "Não Discriminação"; "Ninguém será mantido em escravidão ou servidão; a escravidão e o tráfico de escravos serão proibidos em todas as suas formas" e "Todo ser humano tem direito à liberdade de pensamento, consciência". O foco principal dessa atividade envolveu a "produção feita por estudantes", a partir de "conteúdos aprendidos", no "aprender fazendo, a projeção e a construção" (FILATRO; CAVALCANTI, 2018, p. 40-41).

\subsection{Estratégias significativas de aprendizagem -}

A partir de estudos epistemológicos da teoria de Paulo Freire, foram planejadas e executadas estratégias significativas de aprendizagem com foco na Educação de Jovens e Adultos, tais como: mapas conceituais, aplicativos, roda de conversa e seminários temáticos.

\section{Comunicação por Meio de Mapas Conceituais}

A partir da leitura e análise do artigo "Educação de jovens e adultos: as contribuições de Paulo Freire", foi proposto aos discentes, como recurso didático para a elaboração e interrelação de conceitos, a construção de mapas conceituais.

\section{No Ensino Superior os mapas conceituais são utilizados para diversas finalidades, como auxiliar na sistematização de trabalhos acadêmicos, promoção da aprendizagem significativa, incentivar o trabalho colaborativo, desenvolvimento do pensamento crítico e na resolução de problemas (MACHADO; CARVALHO, 2020, p. 190).}

Com o objetivo de verificar a aprendizagem acerca do referido artigo científico utilizou- se os mapas conceituais. Divididos em grupos, os discentes construíram, em sala de aula, mapas conceituais feitos em papel e lápis. Posteriormente, cada grupo compartilhou no quadro virtual Trello, os seus mapas (Figuras 2).

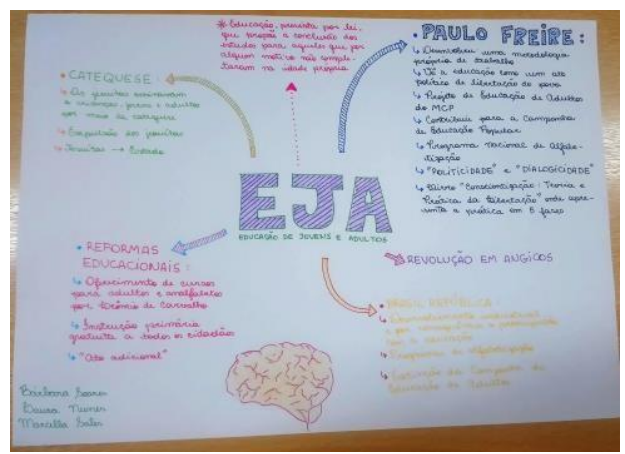

Figuras 2: Comunicação por Meio de Mapas Mentais

Por meio dessa estratégia, a linguagem toma papel de destaque no processo de estruturação conceitual, na medida em que facilita e permite: "assimilar por meio da definição do conceito e de seu contexto e facilitar a comunicação cognitiva interpessoal, enquanto permite a uniformidade cultural de conteúdos conceituais" (CARABETTA JUNIOR, 2013, p. 443).

\section{Aplicativos na educação - Produção de Caricaturas}

Ainda considerando o artigo "Educação de jovens e adultos: as contribuições de Paulo Freire" foi proposto aos discentes a criação de caricaturas, por meio do aplicativo Mirror (Figuras 3 e 4$)$, 

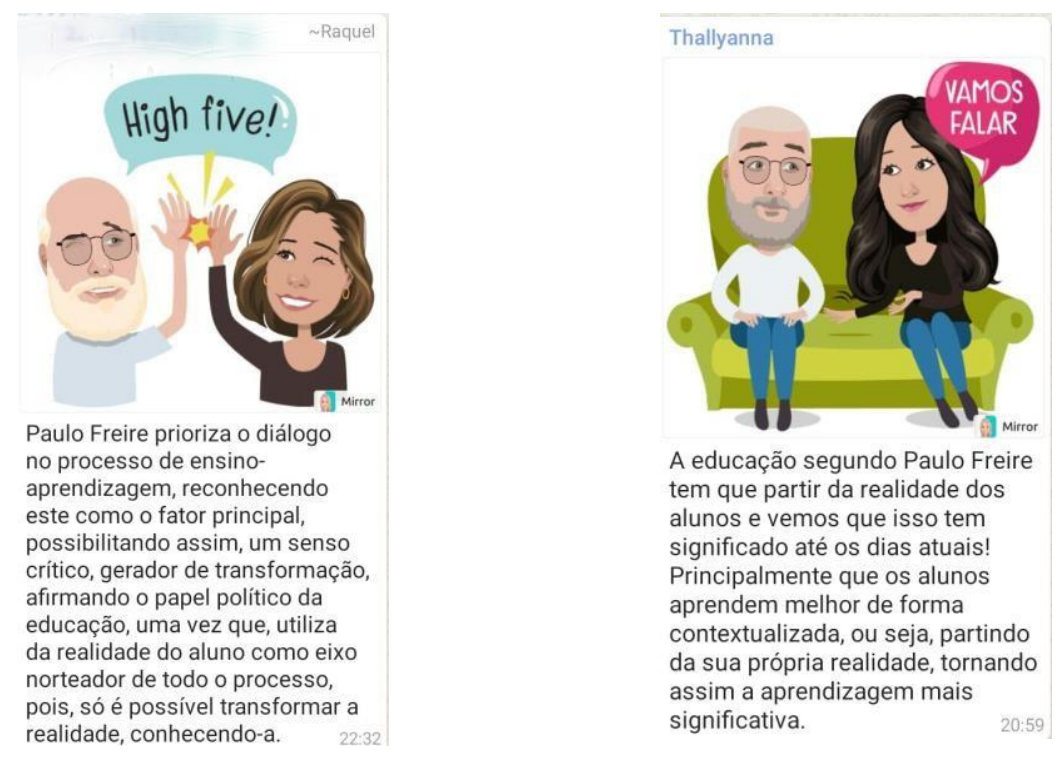

Figuras 3 e 4: Caricaturas - produção final

O ato comunicativo construído, a partir da utilização do aplicativo Mirror, possibilitou a criação de um espaço lúdico, "a expressão da subjetividade livre de qualquer restrição" (BROUGÈRE, 2016, p. 20), da "ampliação da capacidade de expressão do aluno no que se refere à argumentação oral e escrita” (CAMARGO; DAVOS, 2018, p. 27).

O Mirror possui a propriedade de incorporar a identidade do discente em que este, pode ser representado por um "avatar". Nesse aplicativo, o aluno tem a possibilidade de entrelaçar o mundo real e o mundo virtual, expressando a sua essência num movimento híbrido com o conteúdo.

\begin{abstract}
A existência de avatares que representam fisicamente usuários dentro do ambiente imersivo pode contribuir para o senso de presença e copresença.

Essas características se combinam para criar uma experiência psicológica particular, descrita como uma sensação de 'estar lá' ou uma se em uma sensação de presença. Em um contexto multiusuário, também pode haver uma sensação de copresença ou a sensação de 'estar junto' (FILATRO; CAVALCANTI, 2028, p. 172).
\end{abstract}

Essa interação entre o sujeito/aluno com a fundamentação teórica do autor, mediada pelo uso de uma metodologia imersiva, traz a possibilidade da "intimidade" com as ideias apresentadas e a expressão da compreensão subjetiva, enriquecendo as trocas interpessoais.

O uso de aplicativos na educação tem se apresentado como um recurso pedagógico no ensino superior, na medida em que estimula a criatividade do discente, bem como o acesso a conhecimentos de forma diferenciada (CAMARGO; DARVOS, 2018).

\title{
Partilhando Experiências da Educação de Jovens e Adultos
}

O artigo "Educação de jovens e adultos: as contribuições de Paulo Freire" apresenta uma análise da teoria e práxis do método freiriano sobre a educação de jovens e adultos, o que suscitou uma reflexão sobre o cotidiano do profissional que atua na modalidade, mas também gerou uma "curiosidade", uma questão sobre quem é esse aluno da EJA. Para tanto, criou-se um espaço de interação, interlocução com uma ex-aluna.

Esse encontro possibilitou um ato comunicativo, em que os discentes puderam conhecer a realidade da EJA, sua especificidade, expor suas dúvidas com relação: a formação, ao currículo, as 
metodologias adotadas, a dinâmica das aulas, aos recursos utilizados, ao ambiente escolar e a diversidades dos grupos sociais (étnico, gênero, localização espacial, faixa etária). O ponto de culminância do encontro pode ser representado pela questão: "o que mudou em sua vida após cursar a EJA e quais os seus planos para o futuro?.

\section{Seminários Temáticos}

A culminância de todo o processo de ensino e aprendizagem ocorreu sobre a forma de seminários temáticos, a partir de livros de Paulo Freire. A escolha dos livros ficou a cargo dos discentes que decidiram por: Pedagogia da Autonomia, Pedagogia do Oprimido e Educação como Prática de Liberdade.

\footnotetext{
Essa metodologia de ensino coloca o aluno como informante principal e o professor assume a função de coadjuvante do ensino, não menos importante, ao atuar como guia e facilitador. Desta forma, o processo dinâmico de orientação conduz o aluno à direção desejada para organização e aprofundamento das temáticas (RODRIGUES; CUNHA; BRUNO, 2015, p. 770).
}

No decorrer da apresentação, os discentes apresentaram reflexões, correlacionando o ontem e o hoje da Educação de Jovens de Adultos. Destacaram a importância do conhecimento da História da EJA para melhor compreensão do presente e construção do futuro.

O seminário enquanto uma estratégia de aprendizagem, gerou reflexões e discussões sobre o profissional que atua na modalidade EJA, a relação entre docente e aluno, metodologias e práticas e, sobre o aprofundamento da pedagogia freiriana.

O desenvolvimento dos seminários envolveu três fases: 1. Formação dos grupos (livre escolha), escolha do livro e tema a serem discutidos e apresentados. 2. Leitura, estudo e discussão interna nos grupos sobre o tema principal. Esta fase buscou promover a aprendizagem colaborativa, a troca de ideias e experiências entre os participantes. 3. Compartilhamento dos estudos, a partir da conclusão e apresentação dos trabalhos.

Ideias acerca da docência e da discência foram exploradas, destacando-se pontos fundamentais como: ensinar exige pesquisa, respeito aos saberes dos educandos, a criticidade, estética e ética, reflexão crítica sobre a prática. Ressaltaram o respeito à autonomia do educando, a convicção de que mudar é possível, a importância da competência profissional, a compreensão de que a educação é uma forma de transformação do mundo, que ensinar exige liberdade e autoridade, estar aberto ao diálogo, exige curiosidade.

\subsection{Neurociências e Educação - na palma da mão}

A prática pedagógica proposta como primeiro passo de aproximação/conexão do componente curricular com a aprendizagem, teve como objetivo educacional possibilitar aos discentes em processo formativo o reconhecimento de estímulos positivos e negativos a partir de imagens e músicas - comunicação por meio de estímulos visuais e auditivos.

No reconhecimento de cada estímulo, utilizou-se de atributos da gamificação como ferramenta de metodologia ativa. Na neuroeducação, os estímulos devem ser precursores para uma efetiva aprendizagem.

\section{Complexidade cerebral na sala de aula}

A disciplina de Neurociências propôs, também, uma dinâmica concreta por meio da

Persp. Online: hum \& sociais aplicada., Campos dos Goytacazes, 28 (10)60-79- 2020

seer.perspectivasonline.com.br 


\section{PERSPECTIVAS online}

manipulação do encéfalo em modelo sintético (Figura 5). Os discentes aprofundaram o conhecimento sobre a estrutura básica do sistema nervoso experimentando de forma prática.

As atividades pedagógicas apresentadas em sala de aula e na escola devem promover especificamente o aprofundamento dos conceitos e o desenvolvimento de pensamentos mais abrangentes e complexos do cérebro, a fim de saber aplicar e provocar diferentes estímulos no momento certo no processo do acompanhamento nos métodos pedagógicos (RELVAS, 2012, p. 58).

A atividade pedagógica desenvolvida em sala de aula possibilitou o aprofundamento de conceitos, a busca de significado sobre o que se estuda.

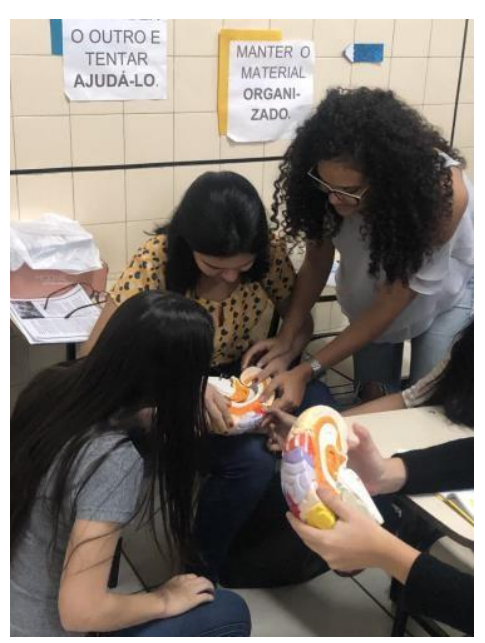

Figura 5: Atividade em sala de aula Complexidade Cerebral.

A exploração do modelo propiciou o melhor entendimento da neuroanatomia, princípio básico da neurociência cognitiva, compreendendo as estruturas que contribuem na consolidação da aprendizagem, localizando as áreas da memória, dos sentidos e das emoções.

\section{Diálogo Teoria e Prática}

Relvas (2012) afirma que o "conhecer e entender o processo de aprendizagem e comportamento", seja por meio de estudos e pesquisas teóricas apresenta-se como um grande desafio para os profissionais da educação.

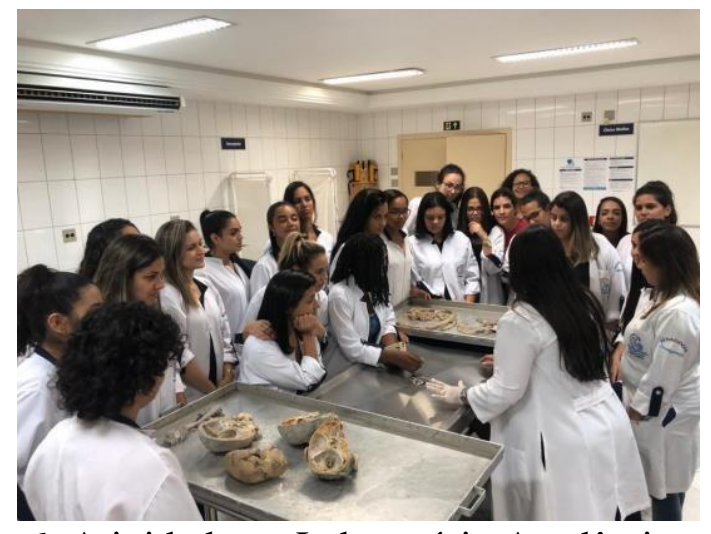

Figura 6: Atividade no Laboratório Acadêmico da IES. 
A aula prática, enquanto um recurso pedagógico para estímulo a aprendizagem, representou a utilização de um espaço fora da sala de aula, que possibilitou aos discentes a integração, associação e compreensão dos conteúdos trabalhados em sala de aula.

\title{
3.4. A Linguagem das redes sociais - um idioma próprio
}

\section{Glossário das Redes Sociais}

Confecção de um glossário contendo códigos próprios da linguagem virtual tais como vdd (verdade), vc (você) e tb (tá bom). Manifestação concreta dos impactos sociais que a língua sofre em cada tempo histórico. Paralelamente a língua padrão, no século XXI, a sociedade realiza atos comunicativos por meio de novos movimentos linguísticos.

Figuras 7: Glossário das Redes Sociais - produção final

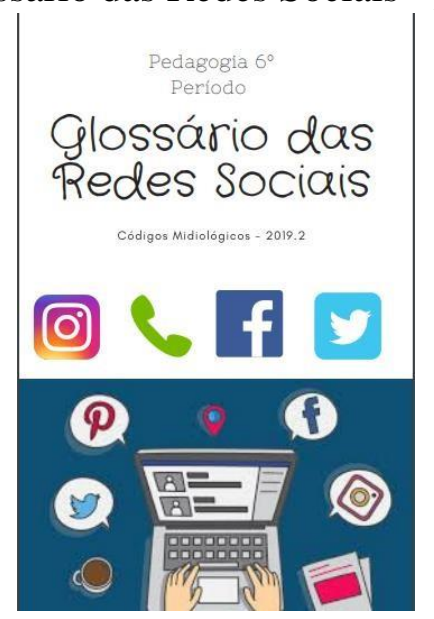

Para Latour (2012 apud PORTO; SANTOS, 2014, p. 9) o termo "social" envolve o "processo de agregações, associações e reassociações, entre atores humanos e atores não humanos". Ator sendo entendido como "qualquer pessoa, coisa, (quase) objeto, instituição que produz agência e que tenha sua participação percebida, ainda que indiretamente, na (s) rede (s)". Redes que passaram a fazer parte do cotidiano das pessoas, não somente por aqueles que fazem e usam da internet, mas que fazem desse espaço um objeto de estudo e análise.

\begin{abstract}
Ator-Rede propõe que o ator nunca age sozinho. Ao agir ele é influenciado (constituído) pelas redes nas quais têm conexões e, ao mesmo tempo, pode representar essas redes, parte de seus atores, bem como influenciá-las. O ator é, ao mesmo tempo, construtor e receptor das redes. Nessa perspectiva, o social, não se deve simplesmente a pessoas, mas ao que acontece pelo princípio da associação, ao que é fluído, em processo de conexão, de forma que tudo está conectado numa rede com múltiplas entradas, sempre em movimento contínuo e aberta a novos elementos (LATOUR, 2012 apud PORTO; SANTOS, 2014, p. 11-12).
\end{abstract}

Argumenta-se, portanto, que, por meio das redes sociais, pessoas se conectam, falam o que pensam ou sentem, produz e divulga textos e imagens acadêmicas e profissionais, quebram tradicionais fronteiras como a do produtor e consumidor, do ensinar e do aprender. Esses movimentos permitem a integração entre professores-pesquisadores e estudantespesquisadores. 


\section{Conversa com quem sabe: o Instagram como forma de comunicação profissional}

A proposta de uma conversa técnica com a assessora de comunicação Rita Cardoso justifica-se pelo poder de influência que o perfil que desenhamos nas redes sociais tem no campo profissional. As discussões foram balizadas no cuidado com as fotos postadas, o conteúdo dos comentários, o que se curte e compartilha. Após o debate, cada discente avaliou seu comportamento nas redes sociais e apresentou uma norma de etiqueta para a comunicação nos espaços digitais.

\section{Dicas de Etiqueta nas Redes Sociais}

Os cards são novas formas de comunicação muito utilizadas no século XXI. Desta forma, surgem como gêneros textuais muito usados na Sociedade Contemporânea. Após estudos na área de Comunicação, produziu-se cards contendo dicas de etiqueta para melhor diálogo nos ambientes virtuais. Depois da produção final, em sala de aula, foram compartilhados no Trello.

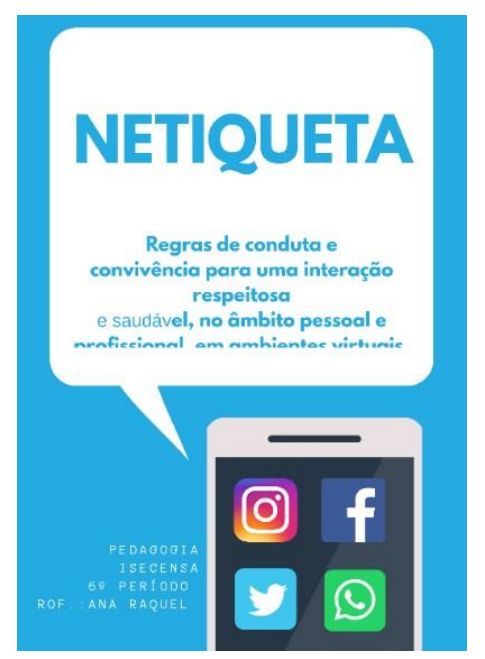

Figuras 8: Dicas de Etiquetas nas Redes Sociais - produção final

\subsection{Projeto de Vida}

A metodologia caracteriza-se por tornar o "Projeto de Vida" um instrumento de reflexão sobre o Aprender a Ser: quem sou eu; qual o meu papel no mundo; meus objetivos e metas; qual o meu projeto de vida, combinado com o Aprender a Conviver: ter a capacidade de comunicar-se, interagir, não agredir, decidir em grupo, cuidar de si, do outro e do lugar em que se vive, valorizar o saber social. Participar e cooperar.

\section{Principais questões:}

1. O que é projeto de vida?

2. O meu papel no mundo. Quem eu quero Ser? Quem eu sou?

3. BNCC e o Projeto de Vida: desenvolva a capacidade de gerir a própria vida, aprendendo a: desenvolver o autoconhecimento; estabelecer metas; planejar e perseguir com determinação, esforço, autoconfiança e persistência seus projetos presentes e futuros; compreender o

Persp. Online: hum \& sociais aplicada., Campos dos Goytacazes, 28 (10)60-79- 2020 seer.perspectivasonline.com.br 
mundo do trabalho, tendências e as novas profissões.

Para o desenvolvimento do Projeto de Vida fez-se uso das estratégias "Roda de Conversa" e "Coaching Educacional". O primeiro momento, contou com a participação de um psicólogo e o segundo com a de uma Coach. O discente constrói seu próprio entendimento por meio da interação e participa ativamente do processo de conhecimento e cognição.

As rodas de conversa se diferenciam de outras atividades grupais, como a terapia de grupo, pois, para o desenvolvimento das rodas, os sujeitos podem se expressar no grupo, mas não é necessário que sejam revelados seus segredos, muito menos é orientada a invasão de sua intimidade. Desse modo, procurando trabalhar com a reflexão e o diálogo, construímos (FIGUEIRÊDO E QUEIROZ, 2013, p. 2).

O Coaching em si é uma abordagem que tem como finalidade o desenvolvimento do potencial humano.

\begin{abstract}
Através da minha história e de algumas outras pessoas que se negaram a desistir diante dos obstáculos, procurei passar uma mensagem de perseverança, tendo em vista que logo entrarão no mercado de trabalho e muitas vezes o caminho é árduo até que alcancemos nossos objetivos e sonhos. Neste momento a perseverança passa a ser a peça chave para o alcance do sucesso" (Depoimento da Coach aos estudantes).
\end{abstract}

Quando agregado com a Educação, o coaching tem função precípua alcançar resultados de aprendizagem, na perspectiva final como processo para o desenvolvimento absoluto da pessoa ou dos discentes.

Ambas as estratégias utilizadas proporcionaram por meio da interação o exercício do pensar compartilhado, o intercâmbio de informações. A prioridade das discussões envolveu "Comunicação e suas múltiplas linguagens" e "As interfaces do ato comunicativo".

Iniciou-se com a exposição e reflexão "Projeto de Vida" e, a partir daí, os discentes apresentaram suas compreensões, suas elaborações sobre o tema, sendo que um era incentivado pelo o outro a falar, "argumentando e contra-argumentando entre si, posicionando-se e ouvindo o posicionamento do outro" (MÉLLO et al, 2007, p. 30)

A etapa final, implicou em um "colocar no papel" pensamentos, sentimentos, emoções, verdades e decisões individuais e coletivas. Cada discente, por meio de uma reflexão para si mesmo, expressou por escrito, questões relativas à tomada de decisão com relação a uma profissão.

\title{
3.6. Prática Integradora e Interdisciplinar: som e imagem
}

Fazenda (1995, p. 113) afirma que "a interdisciplinaridade constrói o conhecimento com o prazer, com o questionamento, com a cooperação, com a heterogeneidade e com o respeito as diferenças individuais."

Nessa perspectiva, foi proposto aos discentes o desenvolvimento de uma atividade integradora e interdisciplinar, considerando as diversas questões abordadas no filme "O Rei Leão", combinado com o eixo norteador/integrador "As interfaces do ato comunicativo" para a prática interdisciplinar "Comunicação e suas múltiplas linguagens".

Para tanto, foi solicitado aos discentes, a construção de um texto dissertativo, indicando os pontos de integração entre as unidades curriculares, assim como a presença de cada uma

Persp. Online: hum \& sociais aplicada., Campos dos Goytacazes, 28 (10)60-79- 2020 seer.perspectivasonline.com.br 
delas no referido filme. A seguir, apresentar-se-á uma breve análise sobre a percepção dos discentes.

\begin{abstract}
"Neste período nos foi apresentado o projeto norteador/integrador "A interfaces do ato comunicativo", que tem como ênfase a prática interdisciplinar "Comunicação e suas múltiplas linguagens". Estas interfaces foram explicitadas por meio de ferramentas como Trello, curta-metragem, construção de infográficos e a "Netequeta", além do filme O Rei Leão. Este projeto evidencia o que Fazenda (1993) afirma, que "a interdisciplinaridade constrói o conhecimento com o prazer". Ao longo do período pudemos constatar a presença de pontos de integração entre todas as unidades, pontos estes que se entrelaçam ao filme O Rei Leão" (Depoimentos das discentes L A.; R. C.).
\end{abstract}

\title{
Neurociências e Educação
}

“[...] buscando formas de estimular o indivíduo à realização de sinapses, buscando compreender a melhor forma de aprendizagem do indivíduo e como superar traumas passados, porém, se não for da vontade do mesmo, ele tem o direito de recusar essa intervenção caso não se sinta à vontade, e nós, claro, devemos respeitar o seu direito. No filme, vimos claramente como Simba passou por várias experiências e aprendizados que remodelaram seu cérebro, criando uma conexão forte de toda aprendizagem que ele recebeu do seu pai e ao longo da vida". (Depoimentos das discentes I. L.; M. R.)

"[...] $\mathrm{Na}$ unidade Neurociências, o ponto referido no filme foi a capacidade de readaptação do Simba, quando se deparou com uma realidade totalmente diferente da sua de costume, o que podemos relacionar com o termo "plasticidade cerebral". (Depoimentos das discentes L. A.; R. C.)

\section{Orientação Educacional, Formação Profissional VI, Estágio e Prática Profissional e Administração e Gestão Escolar}

Nas unidades Administração e Gestão Escolar, Orientação Educacional, Estágio e Formação Profissional o ponto de integração relacionado ao filme se relaciona com a conduta de um Gestor e um Orientador Educacional no que diz respeito às tomadas de decisão, os estilos de liderança estudados e o "Projeto de Vida". Podemos citar que "Projeto de Vida" se relaciona diretamente com a expressão Hakuna Matata, que na língua Suaíli significa "sem problemas". (Depoimentos das discentes L. A.; R. C.)

[...] notamos a presença da Administração e Gestão Escolar/ Estágio e Prática de Formação VI/ Formação Profissional, quando vemos Simba, Scar e Mufasa como tipos lideranças (Liberal, Autocrática e Democrática)". (Depoimentos das discentes B. M.; G. S.)

[...] nota-se aspectos estudados nessa disciplina durante a transmissão do filme "O Rei Leão". Pode-se observar que Scar apenas administrava e não apresentava características de gestão em suas ações, pois possuía péssimas habilidades de liderança. Diferente de Mufasa, que gerenciava os recursos com eficácia, além de respeitar e valorizar todos os membros de sua equipe, sendo assim um verdadeiro gestor democrático e participativo" (Depoimentos das discentes P. A.; T. M.)

\section{Orientação Educacional}

“[...] sobre a importância de se ter um projeto de vida, pois ajuda a visualizar melhor nossos caminhos, nossos sonhos e objetivos para o futuro, e isso envolve um processo de autoconhecimento, e "Autoconhecimento significa estar consciente de quem você é na essência. Descobrir no mais profundo e verdadeiro Eu quais são suas características principais, que fazem você agir da forma que age, ser quem você é." (Cely Cabral, 2019. Slide sobre Projeto de vida)

Persp. Online: hum \& sociais aplicada., Campos dos Goytacazes, 28 (10)60-79- 2020 seer.perspectivasonline.com.br 
Podemos notar que havia uma Projeto de Vida para o Simba desde a infância, que era se tornar o futuro Rei, logo após o reinado de seu pai Mufasa, mas com a perda que teve ele acabou se esquecendo de quem ele realmente era e do seu dever. "Mufasa: Você esqueceu quem você é, e esqueceu de mim. Olhe para dentro de você. Você é muito mais do que pensa que é. Você tem que ocupar o seu lugar no ciclo da vida. Lembre-se de quem você é”. (Depoimentos das discentes I. L.; M. R.)

\section{Códigos Midiológicos}

“[...] foi possível observar as diferentes formas de comunicação, sendo elas escritas, orais, visuais entre outras. Elas auxiliam na forma de interagir uns com os outros.

Foi enfatizado durante as aulas, nessa disciplina, que não é possível haver uma sociedade organizada sem a comunicação, visto que toda interação e organização depende da comunicação, através das linguagens e da construção dos sentidos.

Portanto, o filme "O Rei Leão", demonstra a comunicação a todo instante, com diálogos, músicas, gestos, expressões faciais, entonação, entre outras linguagens utilizadas durante o filme, que são de extrema importância para a convivência, visto que permite a integração". (Depoimentos das discentes P. A.; T. M.)

"[...] vimos em Códigos Midiológicos que as relações que temos nas redes sociais muitas vezes são superficiais, onde temos muitos seguidores, mas poucos são de fato nossos amigos. Como se só a quantidade de pessoas que importasse e não a qualidade, focamos muito no mundo virtual e esquecemos do real. E o filme nos mostra que não importa a quantidade de amigos que temos, de seguidores que conseguimos, mas sim quão verdadeiros são os poucos que temos ao nosso lado, assim como Timão e Pumba foram na vida de Simba, amigos que cuidaram dele, o animaram e mostraram o lado bom da vida, não vivendo só focando nos problemas, e com seu famoso lema "Hakuna Matata" tornaram a vida do leãozinho mais leve.

"Os seus problemas, você deve esquecer, isso é viver, é aprender, Hakuna Matata" (Depoimentos das discentes I. L.; M. R.)

\section{Educação de Jovens e Adultos}

“[...] na unidade Educação de Jovens e Adultos, o ponto de integração no filme foi a questão de determinação e autoconfiança encontrados na força de vontade de concluir os estudos, força de vontade esta que o Simba teve para enfrentar todos os obstáculos e voltar para casa". (Depoimentos das discentes L A.; R. C.)

“[...] na cena em que Scar chega no território das Hienas, podemos notar uma desconstrução de ideias que ele impõe sobre elas, onde o mesmo tem que conquistalas para que possam tornar suas aliadas, assim como um docente da EJA, que precisa conquistar os seus alunos em sua realidade já formada para só assim conseguir ensinálos”. (Depoimentos das discentes B. M.; G. S.)

\section{Educação e Direitos Humanos}

“[...] povo estava passando fome, privando os animais dos direitos básicos de necessidade, como a alimentação. Pois seguindo a declaração Universal dos direitos humanos, em seu artigo 25 vemos que a alimentação é um direito necessário para garantir saúde e bem-estar ao indivíduo, como estudado na matéria de Educação e Direitos Humanos, onde aprendemos como devemos os diretos humanos são importantes e devemos respeitá-los e utilizá-los no meio social e profissional, como futuras pedagogas que seremos. Pois educar envolve trabalhar e reconhecer a dignidade humana de cada um, sem fazer acepção de ninguém”. (Depoimentos das discentes I. L.; M. R.)

“[...] Quando o mesmo volta com as Hienas para o território dos Leões que agora ele é o líder, as leoas perdem os seus direitos (Educação e Direitos Humanos), passando

Persp. Online: hum \& sociais aplicada., Campos dos Goytacazes, 28 (10)60-79- 2020 
ser "propriedades" de Scar e seus comparsas ( as Hienas), mas quando Simba volta as Leoas percebem que não perderam seu espaço e com isso acontece o empoderamento e as mesmas passam a lutar ao lado de Simba para reconquistar o território que já era seu por direito". (Depoimentos das discentes B. M.; G. S.)

\subsection{Pós Discussão: a voz dos discentes}

Na busca por avaliar todo o planejamento e desenvolvimento do Projeto Integrador "Comunicação e suas múltiplas linguagens", desenvolvido pelos docentes responsáveis pelas disciplinas de Administração e Gestão Escolar, Códigos Midiológicos, Educação de Jovens e Adultos, Educação e Direitos Humanos e Cidadania, Estágio e Prática de Formação, Formação

Profissional VI, Neurociências e Educação e Orientação Educacional, buscou-se por meio de "Registros e das Múltiplas Vozes" dos discentes.

O levantamento foi realizado com o auxílio da plataforma de questionários online SurveyMonkey, que possibilitou aos alunos, de forma anônima, expressar suas opiniões sobre toda a prática integradora e interdisciplinar desenvolvida no segundo semestre de 2019. Dos 48 discentes matriculados, participaram desse momento de avaliação 43 discentes (90\%).

Perguntados sobre o uso de metodologias ativas enquanto "[...]formas de desenvolver o processo de aprender, utilizando experiências reais ou simuladas, visando resolver os desafios da prática social ou profissional em diferentes contextos [...]", 83\% (N=37) afirmaram ter sido muito claras e objetivas, $9 \%(\mathrm{~N}=4)$ claras e adequadas e somente $5 \%(\mathrm{~N}=2)$ disseram que foram pouco claras e adequadas. Solicitados a comentar a questão, a voz dos discentes indicou as seguintes metodologias ativas: "Trello". "Sala de aula invertida". "Ensino híbrido, educação maker". "Seminários, debates, atividades lúdicas, depoimentos e outras". "Criação de materiais relacionados a matéria produzidos por nós mesmos". "Aula invertida, aprendizagem maker, o design thinking".

Bergonsi (2020, p. 40) defende que "o conhecimento e a cognição se por interação", o que "implica afirmar que o indivíduo constrói seu entendimento participando ativamente da própria aprendizagem, mediante a experimentação [...] acesso às tecnologias digitais". Todo esse processo desafia o docente a romper com o uso de métodos e paradigmas tradicionais e demanda um docente mediador, facilitador, uma parceria docente-discente.

Em seguida, buscou-se ouvir os discentes com relação a: "as aulas e atividades estavam organizadas, considerando a ação integradora?". Para 89\% $(\mathrm{N}=38)$ discentes as aulas e estratégias de ensino estavam muito organizadas e, para $12 \%(\mathrm{~N}=5)$ pouco organizadas.

\footnotetext{
“Correspondentes e de grande auxílio".

"Foram bem claras e bem dinâmicas".

"As propostas foram muito esclarecedora nos ajudando a constituir um ensino e aprendizagem".

"Conseguiram envolver todos os discentes".

“A conexão ocorreu de forma positiva e clara entre as matérias presentes".

"Desenvolveu criatividade, iniciativa, inovação e colaboração".
}

Persp. Online: hum \& sociais aplicada., Campos dos Goytacazes, 28 (10)60-79- 2020 seer.perspectivasonline.com.br 
"Houve estímulos, então ocorreu uma aprendizagem significativa, além de prazerosa para nós educandas".

Nessa perspectiva, questionou-se os discentes apresentando a questão: "mesmo apoiada em uma matriz organizada por disciplinas, você percebeu a existência de tópicos comuns, ou seja, os conteúdos estavam "direcionados para um mesmo objetivo formativo"? Para 98\% $(\mathrm{N}=42)$ dos discentes os conteúdos foram planejados e desenvolvidos de forma integrada focados no tema e eixo integrador propostos.

\footnotetext{
"Devido ao eixo norteador foi possível ver que os conteúdos estavam mais conectados, gerando uma Aprendizagem significativa para os discentes".

"Tinha matérias com trópicos comuns, com o objetivo de formar docentes pensantes e críticos".

"Nas próprias aulas comentávamos sobre questões que haviam sido comentadas em aulas anteriores, tratando de pontos da integração”.

"Integração recíproca de conteúdos fundamentais, da teoria do conhecimento e da metodologia".

"Estímulo e valorização à participação e à produção intelectual dos estudantes, superando processos repetitivos".

"Gestão participativa na qual os sujeitos do processo inovador são protagonistas da experiência durante o processo, ou seja, da "concepção até a análise dos resultados"
}

Sobre as questões apresentadas, Bacich e Moran (2018) afirmam que todo o processo educativo demanda espaços de prática constantes e diversificados, que estimulem o saber-fazersaber de forma contínua, disponibilizando ambientes de aprendizagem presenciais ou virtuais ricos em possibilidades. As metodologias ativas são estratégias de ensino centradas na participação ativa dos discentes possibilitando a elaboração do conhecimento, por meio da flexibilidade e interação

\section{CONSIDERAÇÕES FINAIS}

Este estudo apresenta práticas integradoras e interdisciplinares desenvolvidas por discentes e coordenadas por docentes que atuam em um Curso de Pedagogia, no interior do Estado do Rio de Janeiro. O trabalho retrata ações implementadas, como um indicativo de inovação nas formas de ensinar e aprender, na reorganização da relação teoria e prática, na relação orgânica entre as disciplinas a partir de metodologias ativas, da flexibilidade do currículo, do estímulo à participação e a produção dos discentes em processo formativo, superando a perspectiva tradicional do ensino e aprendizagem.

A construção de estratégias metodológicas que envolvem metodologias inovativas na educação presencial apresenta-se ainda como um desafio tanto para o docente quanto para os estudantes. No entanto, deve-se reconhecer que o século XXI demanda transformação como palavra de ordem. Metodologias ativas, ações integradoras e interdisciplinares são marcas de um novo tempo. Entretanto, sabemos que os processos de mudança exigem um tempo de transição, de alteração de mentalidade, aderência aos novos paradigmas, flexibilidade cognitiva, domínio das ferramentas digitais e coragem para ousar! É preciso deixar para trás o papel de detentor do saber para ser o mediador do saber e possibilitar um espaço em que o discente, deixe de ser passivo e receptor de conteúdos para tornar-se ativo no processo de aprendizagem.

Persp. Online: hum \& sociais aplicada., Campos dos Goytacazes, 28 (10)60-79- 2020 seer.perspectivasonline.com.br 
Além do mais, a Era Digital traz consigo intensos movimentos na área de Comunicação e suas linguagens. O campo educacional, gradativamente, busca atualizar suas metodologias de ensino e aprendizagem. As práticas educativas que estimulam o protagonismo dos estudantes, denominada metodologia ativa apresenta-se como uma das estratégias para tornar a aprendizagem mais dinâmica e significativa.

O trabalho realizado é um indicativo subjetivo, uma amostragem que pode encorajar profissionais da educação a pensar e repensar sua atuação profissional, tomando como referência a interdisciplinaridade dos debates, as estratégias de comunicação e as linguagens que permeiam o ato comunicativo na Era das Tecnologias Digitais da Informação e Comunicação e, assim, fortalecer os estudos a respeito do assunto.

\section{REFERÊNCIAS}

BERGMANN, J. Aprendizagem invertida para resolver o problema do dever de casa. Tradução por Henrique de Oliveira Guerra. Porto Alegre: Penso, 2018.

BERGONSI, F. Recursos didáticos e aprendizagem estudantil no ensino superior. In: DEBALDI, B. (org.) Metodologias ativas no ensino superior: o protagonismo do aluno. Porto Alegre: Penso, 2020.

CAMARGO, F.; DAROS, T.. A sala de aula inovadora: estratégias pedagógicas para fomentar o aprendizado. Porto Alegre: Penso, 2018.

CARABETTA JUNIOR, V. A utilização de mapas conceituais como recurso didático para a construção e inter-relação de conceitos. Rev. bras. educ. med., Rio de Janeiro, v. 37, n. 3, p. 441-447, set. 2013. Disponível em: http://www.scielo.br/scielo.php?script=sci_arttext\& pid=S0100-55022013000300017\&lng= em \&nrm=isso. Acesso em: 28 nov. 2019.

BROUGÈRE, G. A criança e a cultura lúdica. In: KISCHIMOTO, M. (org.). O brincar e suas teorias. São Paulo: Cengage Learning, 2016.

PEDROSO, C. C. A.; PINTO, U. A. Ações integradoras e de pesquisa na formação inicial do docente polivalente: experiências inovadoras em cursos de Pedagogia no Estado de São Paulo. In: PEDROSO, Cristina Cinto Araújo et al. (orgs.). Cursos de Pedagogia: inovações na formação de docentes polivalentes. São Paulo: Cortez, 2019.

ELIAS, M. C.; FELDMANN, M. G. A busca da interdisciplinaridade e competência nas disciplinas dos cursos de Pedagogia. In: FAZENDA, I. C. A. (coordenadora) Práticas interdisciplinares na escola. 13. ed. rev. e ampl. São Paulo: Cortez, 2013.

FAZENDA, I. C. A. (org.). A academia vai à escola. Campinas: Papirus, 1995.

FAZENDA, I. C. A. Interdisciplinaridade: definição, projeto, pesquisa. In: FAZENDA, I. C. A. (coordenadora) Práticas interdisciplinares na escola. 13. ed. rev. e ampl. São Paulo: Cortez, 2013.

FIGUEIRÊDO, A. A. F.; QUEIROZ, T. N. A utilização de rodas de conversa como metodologia que possibilita o diálogo. 2013. Disponível em: http://www.fg2013.wwc2017.

Persp. Online: hum \& sociais aplicada., Campos dos Goytacazes, 28 (10)60-79- 2020 seer.perspectivasonline.com.br 
eventos.dype.com.br/resources/anais/old_20/1384186533_ARQUIVO_AlessandraAniceto.pD f. Acesso em: 17 out. 2019.

FILATRO, A.; CAVALCANTI, C. C. Metodologias INOV-ativas: na educação presencial, a distância e corporativa. São Paulo: Saraiva Educação, 2018.

MACHADO, C. T.; CARVALHO, A. A. Mapa conceitual como ferramenta de aprendizagem no ensino superior. Revista Contexto \& Educação, v. 35, n. 110, p. 187-201, 2020. Disponível em: https://revistas.unijui.edu.br/index.php/contextoeducacao/article/view/9071. Acesso em: 28 mar. 2020.

MÉLlO, R. P. et al. Construcionismo, práticas discursivas e possibilidades de pesquisa em psicologia social. Psicol. Soc., Porto Alegre, v. 19, n. 3, p. 26-32, Dec. 2007. Disponível em: http://www.scielo.br/scielo.php?script=sci_arttext\&pid=S0102-7182200700

0300005\&lng=en\&nrm=iso. Acesso em: 14 out. 2019.

PORTO, C.; SANTOS, E. (orgs.) Facebook e educação: publicar, curtir, compartilhar [online]. Campinha Grande: EDUEPB, 2014.

RELVAS, M. P. Neurociência na prática pedagógica. Rio de Janeiro: Wak Editora, 2012.

RODRIGUES, F. R. A.; CUNHA, G. A. A.; BRUNO, R. C.. Seminários temáticos como estratégia interdisciplinar de aprendizagem e desenvolvimento de competências em formação avançada. 2015. Disponível em: https://www.conhecer.org.br/enciclop/2015a/ seminarios.pdf. Acesso em: 22 mar. 2020.

TALBERT, R. Guia para utilização da aprendizagem invertida no ensino superior. Tradução por Sandra Maria Mallmann da Rosa. Porto Alegre: Penso, 2019. 